J. Management and Humanity Research

Vol. 2, 2020, 1-10

ISSN: 2582-7766 (online)

Published on 25 January 2020

www.researchmathsci.org

DOI: http://dx.doi.org/10.22457/jmhr.v02a01201

Journal of

Management and

Humanity Research

\title{
Research on E-commerce Service Improvement Based on Text Mining of Negative Review Information
}

\author{
Dongshan Yang* \\ School of Economics and Management \\ Chongqing University of Posts and Telecommunications \\ Chongqing - 400065, Chongqing, China. E-mail: 1654103631@qq.com \\ Received 7 December 2019; accepted 15 January 2020
}

\begin{abstract}
The rise of e-commerce platforms has enabled more consumers to choose to shop online, resulting in a sharp increase in online review data. The large amount of review data hides consumer satisfaction factors for goods or services. These textual data objectively reflect consumer satisfaction. Among them, consumers' negative reviews are more worthy of attention. This article takes 50,000 pieces of data of five representative products on JD.com as the research object. Through word frequency statistics, keyword extraction and cluster analysis of text data, it is concluded that the main factors for consumers' negative reviews are: customer service Attitude, logistics speed, damaged packaging and price fluctuations.
\end{abstract}

Keywords: text mining; K-meams algorithm; online comments; keyword extraction

\section{Introduction}

According to the statistics of the 45th "Statistical Report on Internet Development in China", as of March 2020, the number of Internet users in my country has reached 904 million, and the Internet penetration rate has reached $64.5 \%$. Among them, the number of online shopping users in my country has reached 710 million, accounting for $78.6 \%$ of the number of Internet users, and the growth rate is relatively fast.

The popularity of the Internet has promoted the development of e-commerce. E-commerce sites such as JD.com and Taobao have changed the way people consume. Taking the "Double Eleven" in 2019 as an example, the cumulative transaction volume of Tmall and JD.com totaled 472.8 billion yuan, which to a certain extent reflects the importance of online shopping in the lives of netizens.

With the gradual improvement of e-commerce platforms, after consumers purchase a certain product or service, their evaluation can influence the purchasing behavior of 


\section{Dongshan Yang}

other consumers. A large number of consumer reviews have a huge impact on businesses. The evaluation of products or services can be divided into positive reviews, neutral reviews, and negative reviews. A good evaluation includes a satisfied shopping experience and affirmation of a product or service. A negative evaluation is an evaluation given by consumers after an unpleasant experience of purchasing a product. Studies have shown that negative reviews have stronger influence, more characteristics and explanatory properties. For potential consumers, they will collect existing negative reviews of consumers who have purchased and make purchasing decisions. Therefore, how to reduce or even eliminate the impact of negative reviews on potential consumers is of great significance to e-commerce platforms and businesses.

\section{Literature review}

\subsection{Defining the concept of negative reviews}

Scholars have different opinions on the definition of online negative reviews. Richins (1983) believes that online negative reviews are behaviors that consumers slander a company or a certain product. Luo (2009) believes that the purpose of online negative reviews is to dissuade others from unpleasant experiences and recommendations of certain products. Lee \& Song (2010) pointed out that online negative reviews are formed during and after consumption, and are the expression of consumers' negative experience of products or services. In summary, although scholars have their own opinions on the concept of negative reviews, there is overall consistency, which is mainly manifested in the unpleasant experience and dissatisfaction of consumers after purchasing the product.

\subsection{Research status of online reviews}

There are many perspectives on the research of online reviews. Baek and Ahn (2012) conduct sentiment analysis on collected online review texts. Pu (2019) et al. used SVM to encode the overall opinion sentence for document sentiment classification, and proved its effectiveness with product reviews and movie reviews. Some scholars have studied the impact of the number of reviews (Basuroy, et al., 2003; Liu, 2006) and other related variables (Khare, et al., 2011; Lee, et al., 2008) on consumers, There are also studies on positive reviews (Chevalier, et al., 2006) or the number of negative reviews (Lee, et al., 2008). For example, when studying the impact of negative online reviews on consumer product attitudes, Lee et al. tested the proportion of reviews and believed that as the proportion of negative online reviews increased, consumers' attitudes toward products became worse. Cao Q (2011) et al. examined various functions of online comments (basic style and semantic features), and used text mining technology to extract semantic features from comment texts, and concluded that semantic features have more influence on voting comments than other features. Reyes (2012) provides relevant suggestions for 
Research on E-commerce Service Improvement Based on Text Mining of Negative Review Information

facing language such as sentiment analysis, opinion mining, and decision-making through the analysis of online comments. Chen (2013) believes that the shorter the time interval from purchase to review, the more readers think the review text is useful. Korfiatis (2012) believes that the lower the complexity of the sentence, the more effective readers will think of the review text.

\section{Data acquisition of negative reviews}

\subsection{Data selection}

There are many e-commerce platforms, such as JD, Tmall and Pinduoduo. Since the quantity and quality of online reviews on these platforms vary, the most suitable platform must be selected from among many e-commerce platforms. In this article, JD.com was selected as the data sample source platform for the following reasons:

1. According to website visits and website popularity, a comprehensive ranking of JD.com, Tmall and Pinduoduo (updated on August 30, 2020) through Alexa website ranking is shown in Table 1 below. From the table below, we can see that the Alexa global ranking, Chinese website ranking and industry ranking of JD.com are all above the other two websites.

Table 1: Summary table of ranking of various e-commerce platforms

\begin{tabular}{|c|c|c|c|}
\hline Platform name & Alexa global ranking & Chinese website ranking & industry ranking \\
\hline Jingdong & 11 & 22 & 1 \\
\hline Tmall & 30 & 274 & 6 \\
\hline Pinduoduo & 2319 & 2973 & 102 \\
\hline
\end{tabular}

2. This article is based on negative reviews as a sample of research data. By observing the negative reviews of major e-commerce platforms, the review system varies. Because the JD website has a negative review column, and the data crawling is relatively convenient, this also makes the data selected in this article more targeted.

According to the above analysis, the negative reviews on JD.com have a good representativeness, and useful information for businesses can be mined from the content of the text reviews. Therefore, this article selects negative comments on JD.com as the research object.

\subsection{Data crawling}

The data selected in this article are the negative reviews of five types of products, including fresh food, computers, mobile phones, books, and furniture, which are representative products on the JD website. Since the Python language has many advantages over other programming languages in terms of data crawling, the Python language can use numerous extension libraries to achieve data acquisition. The rules for 


\section{Dongshan Yang}

crawling the review data of returning customers in Python language are shown in Figure 1 , and the process of crawling data in Python language is shown in Figure 2.

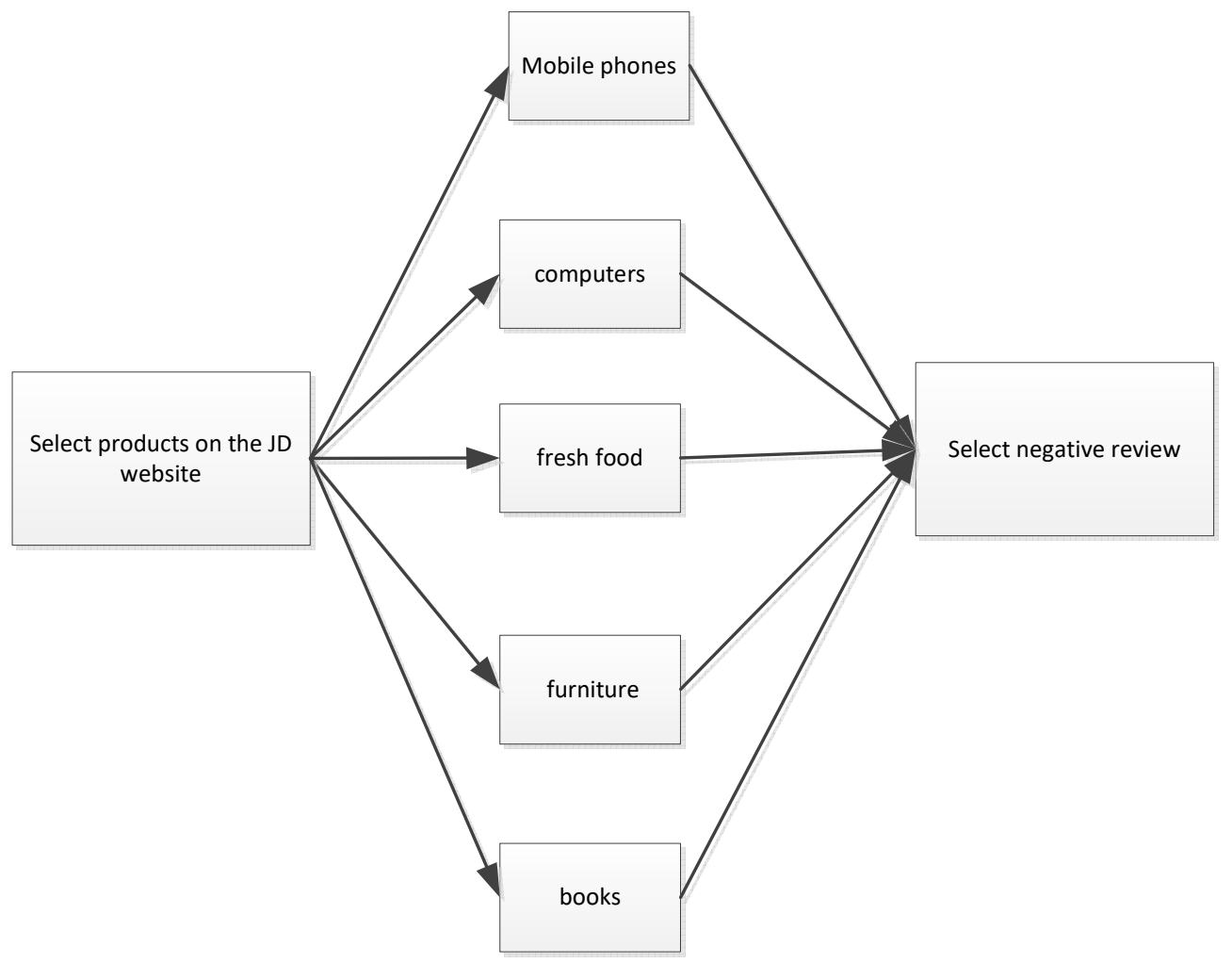

Figure 1: Diagram of data crawling rules

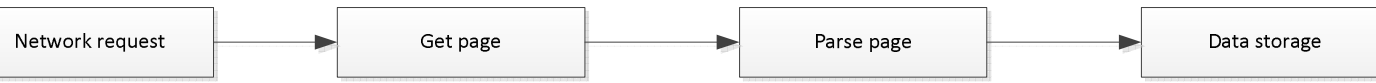

Figure 2: Flow chart of data crawling

\section{Feature analysis based on text mining}

\subsection{Word frequency statistics}

It is of great significance to count the frequency of words appearing in the entire text. The dissatisfaction factors of consumers can be roughly predicted from the word frequency statistics. The frequency statistics of negative reviews of five types of commodities are shown in Table 2 to Table 6. 
Research on E-commerce Service Improvement Based on Text Mining of Negative Review Information

Table 2: Frequency statistics of negative reviews on mobile phones

\begin{tabular}{|c|c|c|c|}
\hline Standby time & 866 & Exterior & 359 \\
\hline Take pictures & 782 & Sound effect & 335 \\
\hline Screen & 746 & battery & 329 \\
\hline Effect & 621 & Recharge & 288 \\
\hline Speed & 601 & Huawei & 275 \\
\hline Headset & 571 & shape & 252 \\
\hline Features & 541 & express delivery & 226 \\
\hline Run & 531 & Few days & 201 \\
\hline
\end{tabular}

Table 3: Frequency Statistics of Computer Negative Comments

\begin{tabular}{|c|c|c|c|}
\hline Customer service & 1201 & Return & 386 \\
\hline Price cut & 612 & A month & 368 \\
\hline Boot up & 594 & Blue screen & 341 \\
\hline Screen & 524 & Few days & 314 \\
\hline Game & 481 & system & 308 \\
\hline After-sales & 461 & effect & 308 \\
\hline Run & 418 & price & 305 \\
\hline Less than & 410 & sound & 299 \\
\hline
\end{tabular}

Table 4: Frequency Statistics of Negative Furniture Reviews

\begin{tabular}{|c|c|c|c|}
\hline installation & 936 & Return & 274 \\
\hline Customer service & 792 & taste & 250 \\
\hline Logistics & 535 & master & 239 \\
\hline Merchant & 424 & work & 228 \\
\hline Ship & 362 & shopping & 224 \\
\hline Screw & 325 & Poor & 214 \\
\hline Product & 297 & After-sales & 203 \\
\hline Image & 284 & Delivery & 198 \\
\hline
\end{tabular}

Table 5: Frequency statistics of negative comments on fresh food

\begin{tabular}{|c|c|c|c|}
\hline Fresh & 1164 & thaw & 296 \\
\hline Taste & 803 & fruit & 281 \\
\hline package & 700 & Head & 270 \\
\hline Customer service & 603 & Find & 262 \\
\hline express delivery & 558 & Cheap & 256 \\
\hline good to eat & 548 & image & 256 \\
\hline
\end{tabular}


Dongshan Yang

\begin{tabular}{|c|c|c|c|}
\hline Taste & 520 & Logistics & 255 \\
\hline Merchant & 397 & time & 252 \\
\hline
\end{tabular}

Table 6: Frequency statistics of negative reviews of books

\begin{tabular}{|c|c|c|c|}
\hline Content & 943 & damaged & 215 \\
\hline package & 621 & Genuine & 212 \\
\hline Customer service & 433 & Logistics & 210 \\
\hline express delivery & 427 & recommend & 194 \\
\hline Piracy & 409 & story & 194 \\
\hline One & 375 & Ship & 183 \\
\hline Paper & 367 & Cover & 182 \\
\hline Print & 350 & translation & 176 \\
\hline
\end{tabular}

\subsection{Keyword extraction}

Keywords refer to words that can reflect the main content of a text to a certain extent. Keyword extraction is an important content in text analysis. Keyword extraction methods mainly include: TF-IDF, TextRank, Rake, Topic-Model, etc. This article is based on the jieba library of Python language for keyword extraction, and its implementation is based on the principle of TF-IDF.

Term Frequency-Inverse Document Frequency (TF-IDF), TF stands for term frequency, calculated as the frequency of the word $w_{i}$ in the document $d_{j}$ divided by the sum of the frequency of all words in the document ${ }^{d_{j}}$, as shown below:

$$
T F_{w_{i}, d_{j}}=\frac{I\left(w_{i}, d_{j}\right)}{\sum_{i} I\left(w_{i}, d_{j}\right)}
$$

Here $I$ represents the frequency count. IDF represents the frequency of reverse documents, calculated as the total number of documents $|D|$ divided by the number of documents containing the word $w_{i}$ plus the logarithm of 1, as shown below:

$$
I D F_{w_{i}}=\log \left(\frac{|D|}{1+\left|\left\{j: w_{i} \in d_{j}\right\}\right|}\right)
$$

The idea of TFIDF is that if a word appears more frequently in a document but less frequently in other documents, then this word is a feature word, so for the word $w_{i}$ in the document $d_{j}$, its TFIDF value is defined as follows: 
Research on E-commerce Service Improvement Based on Text Mining of Negative Review Information

$$
T F I D F_{w_{i}, d_{j}}=T F_{w_{i}, d_{j}} * I D F_{w_{i}}
$$

This article uses Python's jieba library to extract keywords for five types of commodities. The extraction results are as follows:

Table 7: Keyword extraction table

\begin{tabular}{|c|c|c|c|c|c|}
\hline \multirow{10}{*}{$\begin{array}{l}\text { 产 } \\
\text { 竞 }\end{array}$} & $\begin{array}{l}\text { 营 } \\
\text { 竞 }\end{array}$ & 莑 & 䓌 & 蕀 & 咅 \\
\hline & $\begin{array}{l}\text { 営 } \\
\text { 恶 }\end{array}$ & 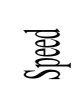 & 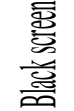 & 屁 & 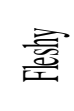 \\
\hline & s் & $\begin{array}{l}\text { 慤 } \\
\text { 空 }\end{array}$ & 㡲 & 嘿 & $\begin{array}{l}\text { 壹 } \\
\text { 竧 }\end{array}$ \\
\hline & 帮 & 䔍 & 总 & $\ddot{\sigma}$ & $\begin{array}{l}\text { 룡 } \\
\text { 릉 }\end{array}$ \\
\hline & 言 & 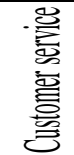 & $\begin{array}{l}\overline{\overline{\mathbf{g}}} \\
\text { 总 } \\
\text { 竞 }\end{array}$ & 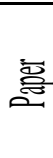 & 莺 \\
\hline & $\begin{array}{l}\text { 嘉 } \\
\text { 妾 }\end{array}$ & 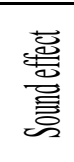 & 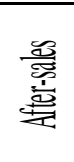 & 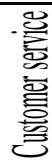 & 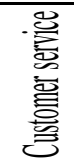 \\
\hline & 跔 & 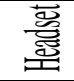 & 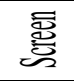 & 氪 & 鄫 \\
\hline & 䉡 & 㦛 & $\begin{array}{l}\text { 焉 } \\
\text { 总 }\end{array}$ & 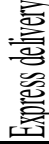 & 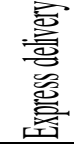 \\
\hline & 噼 & 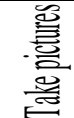 & 言 & 兽 & 范 \\
\hline & 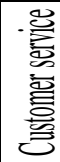 & 言 & 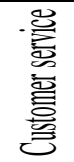 & 譶 & 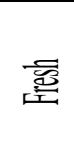 \\
\hline 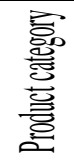 & 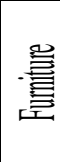 & $\begin{array}{l}\text { 訔 } \\
\text { 言 } \\
\text { 尊 }\end{array}$ & 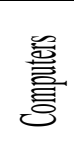 & 商 & 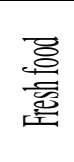 \\
\hline
\end{tabular}

Based on the results of the extracted keywords and the statistical results of the word frequency, these five products all mention the keywords of customer service, express delivery, and logistics. 


\section{Dongshan Yang}

\section{Factor analysis of negative reviews}

\subsection{Clustering algorithm}

Cluster analysis is a process of dividing information into clusters based on the similarity and difference of information. The similarity of objects in the same cluster is higher, and the similarity between different clusters is lower. The degree of similarity between data objects is affected by its value range. In the process of cluster analysis, different clustering methods are used to cluster, and the results obtained are also different.

Common clusters include K-means, MeanShift, DBSCAN, GMMs, AHC, etc. This article uses the most widely used K-means algorithm. K-means algorithm is a simple iterative clustering algorithm that uses distance as a similarity measure. The given data set is divided into $\mathrm{k}$ categories, the center of each category is obtained from the average of all points in the category, and each category is represented by the cluster center.

In the process of clustering, the use of uncorrelated variables will increase the noise in the clustering process and affect the actual clustering results. Therefore, in order to improve the clustering effect, dimensionality reduction (Dawei, et al., 2018) is needed to improve the accuracy of clustering.

\subsection{Clustering results}

This article takes the negative reviews of mobile phones as an example for cluster analysis, and constantly adjusts the $\mathrm{K}$ value. Among them, the four clusters have the best results. Each cluster in the classification is clearly distinguished. The tags and comments corresponding to each category are shown in Table 8.

Table 8: Mobile phone clustering results table

\begin{tabular}{|c|c|c|c|}
\hline $\begin{array}{c}\text { Category } \\
\text { label (topic) }\end{array}$ & High-frequency words (partial) & $\begin{array}{c}\text { Number of } \\
\text { comments }\end{array}$ & $\begin{array}{c}\text { Sort by } \\
\text { topic }\end{array}$ \\
\hline $\begin{array}{c}\text { Customer } \\
\text { service }\end{array}$ & $\begin{array}{c}\text { Customer service, attitude, service, } \\
\text { after-sales, reply }\end{array}$ & 4422 & 1 \\
\hline package & Packaging, broken, bad & 3281 & 2 \\
\hline Logistics & $\begin{array}{c}\text { Express delivery, delivery, service, } \\
\text { arrival, time }\end{array}$ & 1857 & 3 \\
\hline Price & $\begin{array}{c}\text { Reduced price, just bought, less than, } \\
\text { place an order }\end{array}$ & 1639 & 4 \\
\hline
\end{tabular}

\section{Conclusions and suggestions}

\subsection{Conclusion}

In response to consumers' negative reviews of products on e-commerce platforms, combined with the previous negative review text analysis, it is found that the current e-commerce services have the following problems: 
Research on E-commerce Service Improvement Based on Text Mining of Negative Review Information

(1) The customer service responds slowly or does not respond, and the customer service attitude is poor. The communication between the customer and the customer service can understand the service and attitude of the business, so that the business can establish a good service image in the mind of the customer.

(2) The logistics speed is slow, and a small number of express delivery services are poor. The logistics speed will be affected by various reasons. Some businesses choose small logistics companies to reduce logistics costs. The imperfect facilities and management of these logistics companies greatly reduce the timeliness of logistics.

(3) The packaging is crude and damaged when delivered. Some logistics companies do not have good packaging services. If the packages are handled or squeezed during logistics transportation, they are prone to damage or leakage.

(4) The price fluctuates greatly, and the price drops shortly after purchasing the goods. Consumers have given feedback on the fluctuations in the sales price of online shopping products, and even the prices of some products are very different immediately after purchase.

\subsection{Suggestions}

(1) Optimize the customer service system. First, improve customer satisfaction through training on customer service skills and service awareness. Secondly, the communication between customers and customer service is supervised, which can more effectively improve customer satisfaction.

(2) Improve the logistics service infrastructure. Improving logistics infrastructure is the basic prerequisite for improving logistics services. The logistics service infrastructure should be able to be improved from these aspects: firstly, optimize the logistics and transportation equipment, select the corresponding transportation equipment according to the actual delivery goods, to prevent problems such as damage to the goods; secondly, optimize the logistics transportation network and improve the timeliness of logistics Sex. Finally, improve the quality of logistics service practitioners.

(3) Merchants should avoid fluctuations in commodity prices within a short period of time and formulate corresponding price protection measures, so as to more fully protect the interests of consumers. For example, within a certain period of time when consumers purchase goods, if the price of the goods decreases beyond a certain range, consumers can apply for price protection. After the application is successful, consumers should be compensated accordingly.

\section{REFERENCES}

1. M.L.Richins, Negative word of mouth by dissatisfied consumers: a pilot study, 


\section{Dongshan Yang}

Journal of Marketing, 47(1) (1983) 68-78.

2. Xueming Luo, Quantifying the long term impact of negative word of mouth on cash flows and stock prices, Marketing Science, 28(1) (2009)148-165.

3. Y.L.Lee, S.Song, An empirical investigation of electronic word-of-mouth: informational motive and corporate response strategy, Computers in Human Behavior, 26(5) (2010) 1073-1080.

4. H.Baek, J.H.Ahn and Y. Choi, Helpfulness of online consumer reviews: readers' objectives and review cues, International Journal of Electronic Commerce, 17(2) (2012) 99-126.

5. Xiaojia Pu, Gangshan $\mathrm{Wu}$ and Chunfeng Yuan, Exploring Overall Opinions for DocumentLevel Sentiment Classification with Structural SVM, Multimedia Systems, 25(1) (2019) 21-33.

6. S.Basuroy, S.Chatterjee, S.A.Ravid, How critical are critical reviews? The box office effects of film critics, star power, and budgets, Journal of Marketing, 67(4)(2003) 1 03-117.

7. Y.Liu, Word of mouth for movies: Its dynamics and impact on box office revenue, Jo urnal of Marketing, 70(3) (2006) 74-89.

8. A.Khare, L.I.Labrecque and A.K.Asare, The assimilative and contrastive effects o f word-of-mouth volume: An experimental examination of online consumer rating s, Journal of Retailing, 87(1) (2011) 111-126.

9. J.Lee, D.H.Parkand I.Han, The effect of negative online consumer reviews on produ ct attitude: An information processing view, Electronic Commerce Research and App lications, 7(3) (2008) 341-352.

10. J.A.Chevalier and D.Mayzlin, The effect of word of mouth on sales: Online book rev iews. Journal of Marketing Research, 43(3) (2006) 345-354.

11. Q.Cao, W.Duan and Q.Gan, Exploring determinants of voting for the "helpfulness" of online user reviews: A text mining approach, Decision Support Systems, 50(2) (2011) 511-521.

12. A.Reyes and P.Rosso, Making objective decisions from subjective data: Detecting irony in customer reviews, Decision Support Systems, 53(4) (2012) 754-760.

13. Z.Chen and N.H.Lurie, Temporal contiguity and negativity bias in the impact of online word of mouth, Journal of Marketing Research, 50(4) (2013) 463-476.

14. N.Korfiatis, Evaluating content quality and helpfulness of online product reviews: The interplay of review helpfulness vs. review content, Elsevier Science Publishers B. V. 2012.

15. D.Zhao and G.Chen, Construction of implicit semantic multi-label text fast clustering model based on big data, International Information and Engineering Association, (2018) 159-162. 